\begin{tabular}{lcc}
\hline INTERNATIONAL JOURNAL OF & INDUSTRIAL \\
ORGANIZATIONAL LEADERSHIP & MANAGEMENT \\
\hline
\end{tabular}

\title{
The impact of indigenous culture on female leadership in Pakistan
}

\author{
Shafta Manzoor \\ Linnaeus University, Sweden
}

\begin{abstract}
Keywords:

Indigenous Culture, Social Taboos, Social Mobility Issues, Female Career Progress

Correspondence:

shaftamanzoor31@gmail.com

Digging into the experiences of thirty working women, this study examined the barriers imposed by indigenous culture of Pakistan impose on these women. The study followed a qualitative research approach with phenomenological theoretical framework. Fifteen females were interviewed from urban areas and fifteen from rural areas to draw a holistic picture of indigenous culture of Pakistan and its effect on career progress of females. From the data collected, seven categories were initially developed through open coding, followed by three clusters through axial coding and lastly the study created a theoretical framework through selective coding. Findings of the study indicated that indigenous culture strongly affects the career success of working women in Pakistan. The study concluded that indigenous culture of Pakistan puts taboos on females in the form of family behavior, expectations, and the structurally enforced inferior status of females which affects their leadership skills negatively and restricts their career growth. The study concluded that indigenous culture affects career progress of females in negative way and although efforts have been done to give women equal rights in Pakistan, these efforts will become more meaningful if general perception of society about women and their role starts to change which will require awareness programs and cooperation from academic institutions and policy makers.
\end{abstract}

(C)AIMI Journals

\section{Introduction}

It will not be wrong to say that females nowadays constitute half of the population of any country. It is not an exaggeration either to say that women have evolved to contribute half of the potential human capital which can be availed at any competitive economy. In such a 
situation, it is impossible to eliminate the phenomena of gender parity because in the current competitive world one cannot afford to leave any resource unutilized and women workforce is the very prominent one of them (Tran, White, Chow, \& Kluger, 2001). Despite of the societal and economic merits of non-partial employment of women in organizations and the efforts done by globalization to bring all the businesses to one economic forum, it is generally evident that the enrolment of women in entrepreneurial activities and upper level leadership hierarchy is deteriorated under influence of various social, cultural and ethnic norms. Studies suggest that there are significantly lesser number of female entrepreneurs in Asia and other less developed countries of the world, the reason being that these societies have male dominant culture. As a consequence of male dominance in these societies, females are disadvantaged and are not allowed to participate in many aspects of life. Poor representation of females in entrepreneurial positions and professional life is one form of the disadvantage females face as a consequence of discrimination. All over the world, females are indulged in a continuous fight to get equal rights and opportunities and be judged on the basis of their capabilities instead of gender. At the same time, many researchers have been contributing to this effort of increasing gender equality by digging deep in the topic and showing the hidden walls of the concept. However, very little documentation has focused on indigenous culture and the underlying beliefs of societies like Pakistan and the reason of existence of this culture. This brings the need to add more to the literature currently existing in this field and add studies which dig deeper into cultural experiences of females of countries like Pakistan. Females in Pakistan constitute more than half of the population, yet because of cultural taboos and societal restrictions, they constitute only twenty five per cent of the total labor force of the country. This is an alarm that a massive amount of human resource is yet untapped in Pakistan which is neither contributing to economic development nor helping to enhance the overall status of society because of the lack of education and necessary grooming. Pakistan is a developed country in South Asia with a population of more than 190 million people which makes it the world's sixth most populous country.

Women make 52.3 per cent of the total population and most of them, i.e., 71.5 per cent are young ranging from 15-35 years age. Since 1945, the status of females in Pakistan has varied considerably and although females today enjoy better status in society, there is still high persistence of female oppression. Pakistan scores 0.55 in Gender Gap Index, 39 per cent in female labor force participation rate, 0.63 in literacy rate of females, 26 per cent female presence in parliament and 5 years of female leadership in state out of the last 50 years. Apart from these significant figures, Pakistan occupies $141^{\text {st }}$ position out of 142 in female participation to economic development, $132^{\text {nd }}$ in equal educational attainment, $119^{\text {th }}$ in health and survival of females and 85 in political empowerment thus scoring a total of 141 out of 142 countries which is very worrying.

Pakistan is among few nations in which female labor force participation (LFP) is among the lowest in the world and is less than world average of 52 per cent (Pakistan's is 26-30 per cent). In the same region as Pakistan, there are countries like China who have overcome this problem and gained an LFP as high as 67 per cent. LFP denotes the total amount of females working to the total amount of females capable of working. The ratio for Pakistan denotes 
that females are capable of working, but are unable to do so because of cultural and societal barriers they have to face.

Females face inequality in the form of access to education, financial resources, and entrepreneurial opportunities. Even though more and more females are part of higher education, there is no guarantee that these females will become part of the main stream because most of them get married at an early age and are not allowed to join professional life and this increases the education and employment gap. It is clear by now that Pakistani females do not lack necessary education and abilities, but the major thing which restricts them are the unseen barriers from society and prevalent gender discrimination in labor market.

The purpose of this study was therefore to explore the conditions faced by females of Pakistan which restricted their contribution to labor force. This study focused on cultural conditions specifically societal norms and values and their impact on female evolution as leaders. Culture was chosen because culture covers all the day to day beliefs, norms, hidden values, and practices which shape our lives in Pakistan. Closed culture is one of the major barriers to the development of females in professional life as leaders and successful managers.

This study examines how the culture and the underlying glass ceilings have affected personality and struggle of females against cultural barriers. In Pakistan, women are treated as powerful symbols of collective unity and are obliged to follow strict cultural codes which hinder their progress in different fields of life. Pakistan follows patriarchal culture which sustains male power and their control on female members (Phillips, 2003). Highlighting the current situation of gender inequality in the country, this study interviewed 30 working women from different areas of Pakistan and examined the hidden, unknown forces currently faced by working women in Pakistan. The study uncovers the glass ceilings, also known as hidden, unknown forces (Hallinger \& Leithwood, 1998) currently faced by females of Pakistan and examine their impact on women's perception about leadership and their behavior towards career development.

\section{The Literature Review}

So far, significant efforts have been done to explain why females are left behind in different leadership positions and most of the studies conducted till date mostly focus on the barriers faced by females in accessing leadership and climbing the ladder of higher position in organizations. These barriers are identified as either internal/external (Brown, 1997; Sperandio \& Kagoda, 2008), or vertical/horizontal (Weyer, 2007) or cultural and societal (Ingleghart \& Norris, 2000) and they are believed to impact females leadership skills development in positive as well as negative ways (Pounder \& Coleman, 2002). Among these barriers, culture is believed to be the most important one because culture shapes lives of people, their beliefs, the system and structure of a society which impacts female development in personal as well as professional life (Shakeshaft, 1987).

Culture defines and shapes the approach of people towards life which affects their behavior in general and in particular to different entities around them. Therefore, it acts as a very important factor in today's female life decisions and their career success (Shakeshaft, 
1987). Prevalence of traditional norms and values in Pakistan restrict entrepreneurial activities and career progress of females (Wirth, 2001). In Pakistani society, role division of males and females is done at a very early age making females less work oriented and more family oriented (Roomi \& Parrott, 2008). Along with role division, females face many taboos such as Social mobility problems, inability to work late hours and unequal burden of house work (Roomi \& Parrott, 2008).

Rosaldo (1974) describes female's subordination as a historical phenomenon. Since old times, female inferiority has been prominent in the societies where there is a clear split between private and public life and where females are restricted to house. Despite many women movements trying to fight for women rights in third world, females in the third world countries are still deprived of their rights to make their own decisions, decide their life, and choose the career they want and build a vision.

According to Albertyn (2009), in South Africa and similar countries, although laws of equality have already been passed to secure equal rights of females, yet these laws are not applicable in public and private life. Males have power over most of the land, property, and community despite of equal property rights. Culture is a positive recognition and helps in making sense of the world by raising important questions about nature of and relationship between our norms and practices (Ielics \& Runcan, 2012).

Although democracy prevails in these societies and their constitution is based on equal women rights and equality of gender, these aspects of constitution are overlooked and hardly followed because of prevalence of strict male dominant society which doesn't allow authorities to interfere between a male and female's relationship (Ielics \& Runcan, 2012). Culture is defined as the particular way of life of people which encompasses the values these people hold (Rosaldo, 1974). Culture is given high importance and is embedded in people of a particular group; it is a way of making sense of the world and a frame of reference for people of particular group (Wirth, 2001).

In Pakistan, the share of females in upper level management showed a slight increase of only 2 per cent from 1988 till 1995 which is very less as compared to European countries, for example Norway which should increase 30 per cent and Republic of Korea which showed 40 per cent increase in female managers. Wirth (2001) believes that the reason for this small increase is because of presence of strict glass ceilings in the form of norms and values which restrict the activities of females and restricts their journey in managerial positions. One of the major barriers to female appointment at managerial roles is the lack of sufficient education and skills. In Asian countries, girls are usually preferred to take certain areas of education and business studies are considered more of boy's subject (Wirth, 2001).

Since 1994, however the ratio of female students in business studies has started increasing but still the taboo of girls that they do not need to work exists in Pakistan. In Pakistan, role of boys and girls are divided at an early age, females are given the role of family care takers, and therefore, they study the courses which bring empathy, patience, and skills related to house work in them while boys are more interested in business studies and professional life development (Roomi \& Parrott, 2008).

Although females represent 40 per cent of labor force in many countries, they still occupy 20 per cent of top management positions in these countries. Even in multinationals, females 
make only 2 per cent of top managerial positions (Roomi \& Parrott, 2008). One of the reason of this low percentage is the disproportionate division of family roles where females are given strict child care roles and therefore, they cannot give as much time to managerial work as it demands. Females usually have to leave early because their kids are home and they are considered not suitable for managerial jobs; because managerial jobs demand long hours stay at office.

Females are restricted to work for long hours, travel to far places, and relocate their resources (Roomi \& Parrott, 2008). One of the reasons females lack in top management positions is that they are not encouraged enough due to the prevalence of a number of deeply rooted discriminatory social and cultural values as well as traditions.

In Pakistan, females have to face social and familial control and are therefore not allowed to take decisions on their own. Most of the females accept decisions made by others for them. Females have to accept the societal norm of being dependent on males economically (Roomi \& Parrott, 2008). Females are given the impression that males are their controllers and owners of their fate and they have to accept their rules as well as decisions. Males prefer to be the bread earners and do not like females to work and have a contribution in family income because it is considered being coward and eating your wife's money.

Females also face restrictions on their mobility and are not allowed to move freely and travel freely without any male member. In bigger cities of Pakistan, the trend is changing, however staying out for long hours is still considered a social taboo and females who don't stay at home for long hours are culturally unacceptable (Roomi \& Parrott, 2008).

Mobility problem determines the differential access that males and females have to education as well as other services which are necessary to build a managerial career (Rosaldo, 1974). Roomi and Parrott (2008) pointed out that the presence of strong patriarchal culture in Pakistan brings the norm of systemic subordination and females' honor (Izzat). Thus, they have to stay at home and family does not have to face anything disrespectful because of them. In Pakistan, Pardah or "Veil" is used to secularize females from certain roles to keep them at home within the family and restrict their social activities which are the reason why females are very less at managerial positions.

Because of the restricted society and culture, female's mindset about life changes and their interests become highly family oriented (Rosaldo, 1974). Females accept the fact that they are to be blamed for everything wrong that happens to their family and they are made to sacrifice their wishes and career for family and husband. This underlying thought affects female leadership and entrepreneurial ventures in Pakistan (Roomi \& Parrott, 2008).

Most of the entrepreneurs and females in managerial positions occupy the position because of some unforeseen event such as death of their family breeder and earner which leaves the responsibility on them (Rosaldo, 1974). Females have to face social barriers; however, they keep fighting and they have to work hard for their education and skill development, and at the same time they have to fight with their societal values and cultural norms. As they are compelled by circumstances to occupy a certain position, females are usually not motivated enough to bring creativity and diversity in their business and restrict it to the amount of growth which gives them sufficient money to carry family's living.

Because of the restricted society and culture, female's mindset about life changes and their 
interests become highly family-oriented (Rosaldo, 1974). Most of the females pursue professional career because of some unforeseen event such as death of their family breeder and earner which leaves the responsibility on them (Rosaldo, 1974).

A few barriers of successful career of females including culture and norms of the particular country, lack of role models, lack of political voice of females, and roles assumed by society were identified. Females make 3 per cent of total entrepreneurs in Pakistan and these 3 per cent are restricted to some specific fields such as fashion designing, garments, and food sectors. The reason is that females are preferred to adopt professions in which potential customers are usually females as culture of Pakistan does not find it appropriate that a female deal with males all the time at work.

Business environment for women in Pakistan constitutes of two categories. First category is social, cultural, and traditional elements and second category consists of the constitution, structure, policy, and institutional mechanisms and this category is shaped rigidly by first category. In Pakistan, first category is traditional and rigid which poses difficulties for females in the form of social restrictions, restricted funding opportunities, lack of information and infrastructure, low level of education and insufficient skills, and low level of networking.

The research studies consulted for this study helped to develop a background on the native culture of developing countries especially Pakistan and helped to know how this culture affects equal gender treatment and equal opportunities. From the literature studied it is observed that females are usually given inferior status in developing countries and they are excluded from higher positions and restricted from getting involved in society and economic development because of societal and cultural barriers.

\section{Research Questions}

To unveil the objectives discussed above, the following research questions are addressed through this study.

1) What are general norms in indigenous culture of Pakistan?

2) How does indigenous culture affect career success of Pakistani women?

\section{Method}

Since quantitative approaches are insufficient to capture and paint the particular picture of this study, I have chosen a qualitative approach for this study (Strauss \& Corbin, 1990). This research follows an exploratory philosophy to understand the conditions effecting career success of females of Pakistan. This study was based on qualitative approach using grounded theory approach whereby data collected from thirty respondents was used to analyze the factors effecting career success of females in Pakistan.

This study is based on the methodological view of grounded theory which is a method whereby a theory is built out of the data collected (Strauss \& Corbin, 1997). As a grounded theorist, I began the process by keeping an open mind towards the issue of gender inequality. This research did not begin with a theory developed pre-hand, instead it started by gathering information on current situation of females in Pakistan focusing on the barriers they currently face and the reasons for persistence of these barriers in Pakistani society. After getting an 
overview of the current situation of females in Pakistan, this study chose indigenous culture as the dimension to be explored further in this study.

As this study focuses on exploring the effect of culture of Pakistani female's leadership success stories, the research started with carefully identifying and selecting subjects for the current study. The next sections describe the selection of participants, interviews, and data analysis process. This study follows the four phases of grounded theory as explained in Figure 1.

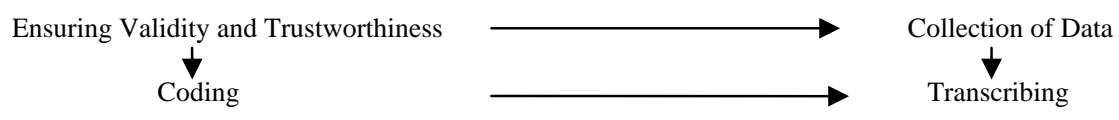

Figure 1. Grounded theory research process

Data was collected in two phases; in the first phase, an interview script was prepared and tested on ten individuals who were close friends and family members and they were asked if the interview script was appropriate and it was made sure no one found it offensive or too personal. Once the ten members provided their reviews about the interview script, it was changed according to the feedback and a final version was prepared to use later in this study for collecting data and conducting analysis.

Choosing right participants is an essential step to make the study credible (H. Rubin \& I. Rubin, 2005). Participants for this study were working women with a minimum of two year experience in their current job and the participants who were experienced enough in their profession were chosen; so that the data collected from them could be meaningful, thoughtful, rich, and full of experiences. Additionally, I contacted people I have known for years and who are now pursuing professional life. This helped me gather data which was deep and personal and sensitive to some people too and which would not be possible to get from strangers because Pakistani culture is closed and people do not prefer to share their experiences with strangers openly. Therefore, I knew most of the people I interviewed and the rest were referred by my friends so they didn't have any confidentiality issues either.

I chose a sample size of thirty working women; fifteen from rural areas and fifteen from urban area. The procedure used to invite participants was to phone them, explain the situation briefly, and ask for their permission to conduct an interview. The ones who agreed were emailed the research aim sheet which helped them understand the questions before the interview, so they did not become blank during the interview. The sheet also ensured the information would be kept confidential and highlighted how information will be used to ensure participants know their information is protected and not misused in any aspect. In the email, I asked them about the date and time of the interview.

For this study, interviews were designed to explore how culture has affected the personal, interpersonal, and external development of females. The interview script included open questions covering general information, stories of career development, and how culture affected their skills and career opportunities. Interviews were conducted through Skype and time was set up to the convenience of participants. Females were told at the start of interview that the participation was voluntary and not forced and meant no harm to them. Participants were allowed to feel free to decline any interview questions and discussion they did not feel 
comfortable talking about. It was made sure that females do not become upset talking about their personal life and it was made sure that no offensive language is used against anyone.

Each participant was interviewed individually for approximately 30 minutes and some interviews took 40 minutes. To generate a conversation and discussion instead of structured interviews, order of the questions was changed and the questions were asked not exactly as written but were melded in different ways to extract information from different participants. Moreover, the follow-up questions were added wherever needed in order to keep the conversation going and to avoid ambiguous and short responses. While conducting the interviews, I made careful memos and took notes for everyone, so I compared transcriptions to memos and notes in later stages. All the interviews took two month time to be conducted.

In order to conduct analysis from the data gathered through interviews, the recorded data was written down and converted into transcripts. From the transcripts prepared, coding was done and themes were developed as discussed later. One interview took four to five hours to transcribe. While transcribing, I looked back at my notes and memos and I had prepared and tried to relate the events when I was taking notes. Transcription of every interview was done right after the interview was conducted and this helped me reflect on my work with more depth and clarification. Transcription was in both English and Urdu because most of the women interviewed used a mix of both languages and later it was translated into English. I took care of the fact that wrong translation will affect my research quality and therefore, selection of words was done very carefully and accurately. This study is based on analysis model proposed by Braun and Clarke (2006). In the first step, transcripts were read many times to familiarize myself with data and to refine the concepts emerging out of the data. In second step, information was searched for and coded in a systematic way to ensure it matches the themes discussed in literature review. In third step, I moved on to rereading the transcripts carefully and the notes and memos I took earlier. This helped me ponder upon the themes and codes already developed and looked for new themes if any. In fourth stage, I matched the themes emerging to my research questions to ensure that my research is valid and is measuring what it is supposed to measure. In this step, I also built relations between my themes, sub-themes, and came up with a thematic map. In fifth and last stage, I reported the findings and began with discussion of my data analysis.

In order to ensure validity and trustworthiness at every stage of this research, this study was carefully designed at every step. While schematizing, it was made sure that the theoretical presuppositions of the study are sound and research questions were logically derived as emphasized by Kvale and Brinkmann (2009). After carefully reviewing literature, research questions and major concepts of the study were redesigned and made more focused and clear. In next stage, it was made sure that the research design and research methods fit into the purpose of the study and as described earlier, qualitative approach and semistructured interviews were chosen as the most suitable approach to this study.

To ensure quality of the interview research, participants were chosen very carefully, making sure they are interested in becoming part of the research, open to the topic, experienced and knowledgeable (H. Rubin \& I. Rubin, 2005). Purposeful sampling was done for this study which allowed me as a creator of knowledge to select the participants intentionally and carefully (Creswell, 2002). 
While conducting interview, validity and trustworthiness depends on the subjects and the interview structure as well (Kvale, 2006). According to Walford (2001), there can be situations where respondents may lie or withhold information because they have little to gain from telling an interviewer their innermost secrets. To avoid such situation, good relations were built with respondents by creating a relaxed environment and stress free discussion (Johnson \& Turner, 2003).

In data analysis stage, it was made sure that data interpretation is sound and unbiased as emphasized by (Walford, 2001). To ensure validity in the last stages of this research, transcriptions were carefully made and neutrality was ensured from the author's end. Lastly, to ensure trustworthiness of this research, it was made sure that that the analysis actually falls in the context of this research and answers the research questions fully and as explained by Williams and Morrow (2009), it is a very important step to ensure trustworthiness of the study.

This research started by conceptualizing facts to open coding which was done from the information gathered through transcriptions. Through open coding, seven categories were developed in this research. To develop categories, similar questions of the interview script were put in one category and the answers were analyzed. After open coding, transcripts were reread and compared to notes developed at the time of interview in the form of memos.

From the comparison and careful reading, similar categories were put under one theme through axial coding. Axial coding helped to rearrange the data more carefully and put similar data in same categories thus helping develop major themes of the research. After axial coding, the next phase integrated all the categories along their dimensional levels to create a framework out of my research, validate the statements made already through open and axial coding, made the relationships, and fill in categories which need to be worked upon. Sampling was done very deliberately at this point and as a researcher, I looked for events or incidents instead of focusing on people. This phase led me to the development of theoretical framework on development of female business leaders.

Thirty women participated in this study where fifteen were from major cities while fifteen were from smaller cities. Fifteen females interviewed were from Gujranwala, Sheikhupura, Sialkot, Multan, and Bahawalpur while the rest were from Islamabad, Lahore, Karachi, and Faisalabad. The participants ranged from an age of 26 years to 42 years. They have been working in different organizations both small and large for at least two years. Almost all the women held significant positions in their teams and were performing significant leadership responsibilities in the team.

Of the females interviewed, six were holding different positions in academic institutions and were working in different academic institutions; four were entrepreneurs and had businesses of their own while the rest twenty were working in different fast moving consumer goods companies (FMCG). Out of the thirty participants, eighteen were married, three were engaged, and nine were single. In general all these females held business degrees (Bachelors, Masters) from different business schools of Pakistan and three held Master's degree from London. 


\section{Open Coding}

The conversations revealed that conservative culture of Pakistan imposes many taboos on female's personal as well as professional life and affects their vision and perception about themselves. Cultural barriers exist in the society and have an impact on the decision making power of females. Most of the respondents feel they are controlled and do not have the power to make their basic decisions which affects their approach towards life. The respondents believed that inability to take their decisions overtime makes them reluctant to pursue their dreams. Almost all the respondents believed that their decisions were taken without their involvement because their point of view was not considered rational and mature.

Respondents also believed that the inability of taking their decisions results in a lowered self-confidence which affects the performance of females in professional as well as personal life. Almost all the respondents believed that cultural barriers appear in the form of social mobility where females are not allowed to live alone in different cities from their home town and also not allowed to travel to distant cities. This restricts the success and expansion of female entrepreneurs who restrict themselves to their local area. Also, most of the females have to give up on job opportunities because they are not allowed to move freely and asked to stay with family and work at a place close to home.

Findings from the interviews indicated that cultural taboos exist as a big barrier to the development of career of females in Pakistan. Females face the issue of social immobility that is why most of the entrepreneurial ventures remain small scale and under developed and most of the females give up on better job opportunities in bigger cities.

Another important factor derived from conversations was the ownership of females by their family and the concept that females have to submit themselves to their primary as well as secondary family. Most of the respondents said that their families believe to be their owners and females have to submit themselves fully to their families and husbands which makes it difficult to choose a path of their own and pursue their dreams.

Females are considered responsible to keep relationships and to save relations and they have to sacrifice themselves and their aims. Culture imposes the tradition of females being answerable for everything they do and complying with all the decisions made for them. It appeared that females are not able to make their decisions and instead they have to rely on decisions already made for them which restrict their career development.

Females are considered the honor of house and therefore they are expected to behave in a very careful manner; so, no one can point a figure on them. It also appeared that females are expected to behave in a certain way which affects their progress. Females are expected to be loving and caring and their rationality is doubted. As people assume that females are caring, their decisions are doubted on rational basis and this is why most of the companies give them positions which involve more emotional and less rational decisions.

Females are expected to make sacrifices and save relationships from breaking and this is why they have to sacrifice themselves to keep relationship strong and living. Females find it very challenging to balance work and family life because of the uneven distribution of house work. Most of the females feel extra tired and are unable to manage their house work as well as job. Single working girls, however, do not face this problem so intensely because they are usually taken care by their mothers and have maids for their work. This is one of the reasons 
that females prefer to work when they are unmarried but as soon as they get married they find it very tough to balance responsibilities at home and work. Lastly, culture has a very strong negative impact on success of females in their professional life because of the role expectation, social immobility issues, decision making power, and restrictions it imposes on females.

From open coding done above, following initial themes can be extracted such as decision making power of females, social mobility issues for females, role expectancy from females, female subordination, structurally enforced inferior status of women, work and family life balance issues, and lastly the effect on skills development of females. In next step of analysis, axial coding is done and categories are further integrated into sub themes on the basis of their meaning and interpretation.

\section{Axial coding}

In this stage, further digging was done in the data collected and conceptualization was done to integrate categories of this study. The seven categories developed were put in core categories in order for a theme to emerge out of these categories. All the categories were analyzed on parallel basis and compared to create a relation among them. After carefully reading the transcriptions again and comparing with memos developed during interviews, the seven categories were finally broken down in three clusters, namely cultural taboos, skills , and status of women. Table 1 shows a description of the clusters and their subsequent categories.

Table 1

Clusters and Categories Developed by Axial Coding

\begin{tabular}{lll}
\hline Cluster 1: Cultural Taboos & Cluster 2: Status of Females & Cluster 3: Leadership Skills \\
\hline Category 1: No decision making power & Category 1: Female subordination & Category 1: Vision development \\
Category 2: Social immobility issues & Category 2: Role expectancy from females & Category 2: Self confidence4 \\
$\begin{array}{l}\text { Category 3: Work and family life } \\
\text { imbalance }\end{array}$ & Category 3: Structurally enforced inferior & \\
\hline
\end{tabular}

\section{Selective Coding}

This research examined the effect of cultural taboos on women leadership and entrepreneurship abilities in Pakistan. After developing three main categories out of the information gathered from interviews, all the themes and clusters were rearranged and compared to the primary data in order to create a theme for this study. Findings of the study indicated that the overall native culture influences female's abilities to excel in their career and is the main reason of poor representation of women in organizations especially at senior positions.

Indigenous culture of Pakistan gives rise to conservative organizational culture which affects career progress of females in their respective fields. After carefully reviewing all the categories, indigenous culture appeared to be the main theme of this study out of which a theory is developed in next section. Indigenous culture is the culture currently practiced in the country and this study examined that indigenous culture had negative impacts on females of Pakistan because of the conservativeness and male power in society. 


\section{Thematic Map}

Culture is a very unique practice and therefore impact of every nation's culture on their women is very unique and varies from country to country. The study indicated that indigenous culture of Pakistan has a very significant impact on women's leadership skills including their vision development, self-confidence, perception about themselves, and selfrecognition and this impact affected their growth in organizations and their success at work. From the analysis conducted, it is evident that females in Pakistan face discrimination because of the cultural and discriminatory practices affect their personal development as well as career development. From the previous discussion, following thematic map is generated.

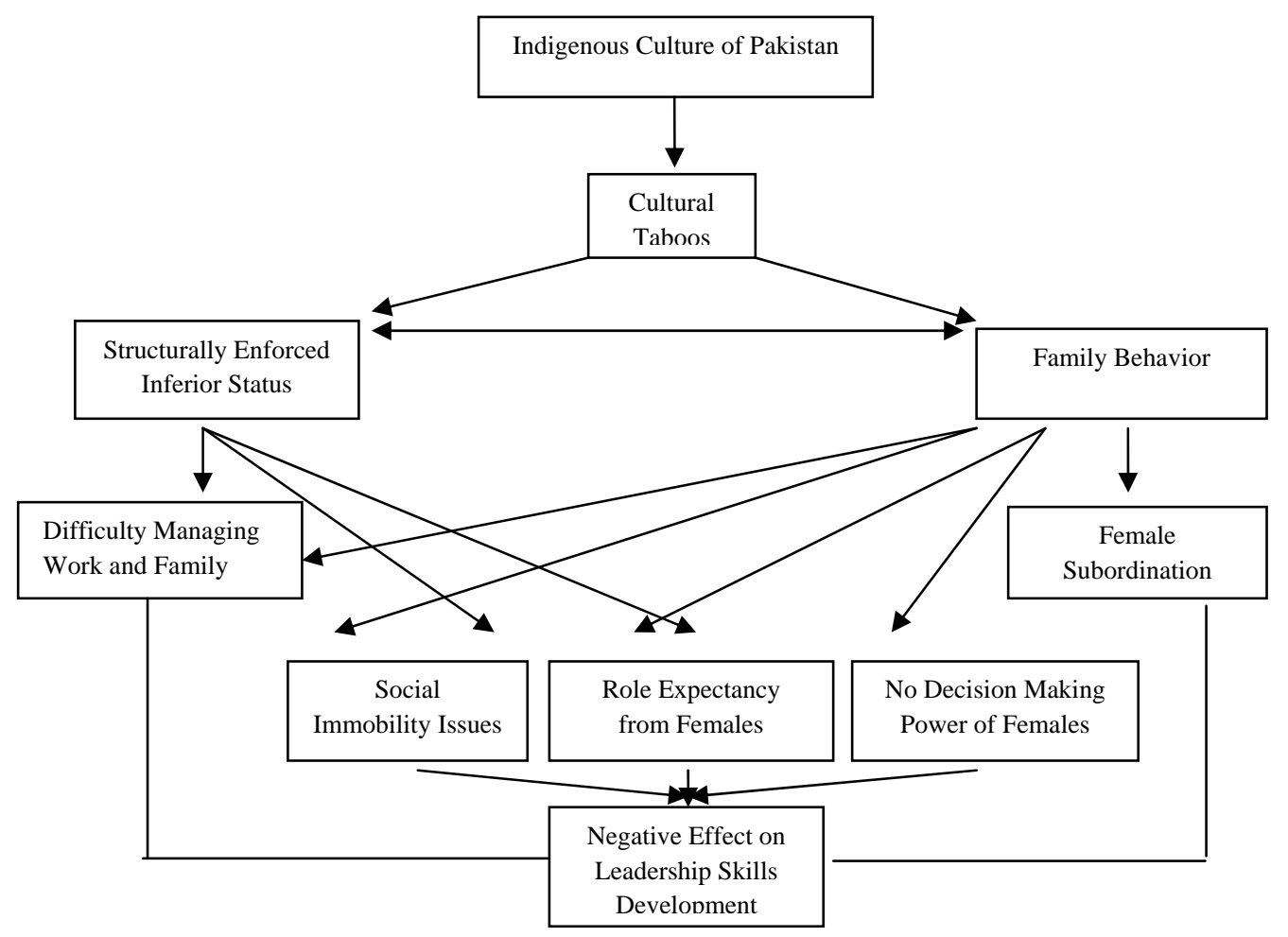

Figure 2. Thematic map of the study

As it can be seen in Figure 2, in the thematic map, indigenous culture of Pakistan imposes different types of barriers on females. These barriers prevail in the form of behavior of family members and the structurally enforced inferior status of females in Pakistan. These two factors affect the decision making power, social mobility power, role expectancy, subordination of females, and domestic work life balance.

\section{Discussion}

The discussion emerged out of this research was theoretically and practically in line with most of the literature consulted on women leadership. Specifically, women's career growth and leadership skills were strongly restricted due to cultural barriers such as social 
immobility, family and work life balance, role expectancy from females, lack of decision making power, and inability to have an independent life of their own.

The present study examined women's leadership from cultural perspective and the findings revealed to have significant contribution to existing literature body and to the development efforts in countries like Bangladesh, India, and China where gender equity is still in question especially at professional level.

Culture is a very unique practice and the impact of every nation's culture on their women is very unique and varies from country to country. A unique finding of this study was that women are disadvantaged in many aspects of life because of the perceptions society holds about them and because of the roles they are given since their early childhood.

They suffer from gender stereotypes which are a result of prevalence of Confucianism concept in society. Although Pakistan had a female prime minister and it is encouraging participation of females both in politics as well as professions, females are still seen from the traditional culture's eyes which restricts their progress and success.

The study indicated that indigenous culture of Pakistan has a very significant impact on women's leadership skills including their vision development, self-confidence, perception about themselves, and self-recognition. This impact affected their growth in organizations and their success at work. Socio-cultural norms with traditional gender roles and male dominance influence female's leadership practices and career success and contribute to under-representation of females in most of the work positions.

\section{Conclusion}

A man has 46 chromosomes. But does a woman have 45 of them? The truth is that the divine hand gifted both men and women with similar biological assets. But did that divine gift them with similar social setups? The real answer to this question rests under countless theories and thinking paradigms. In fact, not even a single non-controversial theory exists on face of earth to prove any side of this question.

But one of the most interesting facts is that most of the voices raised on this issue have emerged from the western world. The divide on this issue between east and west seems greater than any other divide.

Situation is changing now. Globalization has resulted in convergence of ideas on massive scales. The East-West divide is now suffering from ideological as well as ontological proliferation. The issue of anti-feminist social setups is also facing this trend of proliferation. However, it is really important to understand that the proliferation of eastern concept of feminism has not seen a set and definite filter to gauge invalid arguments from valid ones. Over time, many invalid arguments have generated such thinking paradigms as have inappropriately portrayed the image of Eastern feminism in Western world. This has mainly happened because Eastern scholars have been too late to join the research club in this regard.

This research examined how culture affects career progress of Pakistani women in positive ways as well as negative ways. The study followed qualitative research design and was conducted using a phenomenological theoretical framework. Thirty women from rural and urban areas of Pakistan participated in this study and all the participants were interviewed using Skype and most of the interviews were in national language Urdu. Although Pakistani 
society is facing a huge shift with more and more females emerging as entrepreneurs and more females working in big multinationals, the cultural shift is slower as compared to globalization and development of females in rest of the world. It was also observed that closed culture of Pakistan imposes barriers such as social immobility, inability to take decisions, unequal burden of domestic work, role expectancy, and female subordination to male members.

The study also observed that almost all the participants were very positive and they wanted to excel in their career despite of the hardships they had to face. One very important finding of this study was that the females do not lack necessary skills, instead the structurally enforced inferior status of females in society decreases their chances of being selected for different jobs. Almost all the participants believed that there is a need of general awareness in the society regarding female rights.

Society needs to be educated on the issue and more importantly females need to be given incentives to start their own projects at small scale; so, they can bring more opportunities for either females and can fight the barriers imposed by culture. Most of the females also believed that countries like Pakistan need more female role models so they can look up to someone and learn how to fight for their own rights. Almost all the participants pointed out that seeing new entrepreneurs in different fields and young girls fighting for their rights and making it to their dreams motivates them and gives them strength and they feel the society will change soon if females keep emerging as they are today. This study had important implications for bringing gender equity in societies like Pakistan where females are still not a big part of labor force and do not play a significant role in economic development. The arguments raised all over the world related to women oppression in the east are entirely mistaken. In fact, most arguments are valid. However, there is a strong need to understand contextual factors to comprehensively understand the real matter.

Moreover, it is important to note that trends are changing in the east now. Today, there is a wave of pro-feminist paradigm in different developing countries. One clear example is that of Pakistan where parents do not want to educate their children irrespective of gender. Parents have now become more aware of the right of their daughters to get married by their own choice. Parents have become more concerned about the career opportunities for their daughters which are a ray of hope to see future where females will have a life more liberal, equal, and successful. As this study was conducted on a small scale and focused on few areas of Pakistan, there are certain limitations attached to it. Firstly, the sample size was small and cannot be attributed as a representative of the whole of Pakistan. This study was conducted in Punjab which is one of the most developed provinces of Pakistan.

However, situation of females in other provinces is worse where religious extremism and ownership of females is very high and females are killed for any disobedience against family. Punjab is the most developed region of Pakistan with all the bigger and developed cities and therefore this study did not bring all the in depth prevailing taboos against females of tropical areas.

For future research, it is recommended that research should be conducted on a large scale and in the tropical areas of Pakistan in order to get a better picture of these areas. Moreover, comparison should be drawn between Punjab and the rest provinces so that improvements 
can be made more effective and it can be known which areas need a certain kind of method to improve situation of females.

\section{References}

Albertyn, C. (2009). The stubborn persistence of patriarchy. Gender Equality \& Cultural Diversity in South Africa, 2, 165208.

Braun, V., \& Clarke, V. (2006). Using thematic analysis in psychology. Qualitative Research in Psychology, 3(2), 77-101.

Brown, H. (1997). Equal opportunities policy. In H. Eggins (Ed.), Women as leaders and managers in higher education (pp. 109-124). Buckingham, Great Britain: The Society for Research into Higher Education \& Open University Press.

Creswell, J. (2002). Educational research: Planning, conducting, and evaluating quantitative and qualitative research. Upper Saddle River, N.J: Merrill Prentice Hall.

Hallinger, P., \& Leithwood, K. (1998). Unseen forces: The impact of social culture on school leadership. Peabody Journal of Education, 73(2), 126-151.

Ielics, B., \& Runcan, P. L. (2012). The profile of the successful woman manager in Romania. Procedia-Social \& Behavioral Sciences, 46, 909-911.

Inglehart, R., \& Norris, P. (2000). The developmental theory of the gender gap: Women's and men's voting behavior in global perspective. International Political Science Review, 21(4), 441-463.

Johnson, B., \& Turner, L. A. (2003). Data collection strategies in mixed methods research. In A. Tashakkori \& C. Teddlie (Eds.). Handbook of mixed methods in social and behavioral research (pp. 297-319). Thousand Oaks, CA: Sage Publications.

Kvale, S. (2006). Dominance through interviews and dialogues. Qualitative Inquiry, 12(3), 480-500.

Kvale, S., \& Brinkmann, S. (2009). Interviews: Learning the craft of qualitative research interviewing (2 ${ }^{\text {nd }}$ ed.). Thousand Oaks: Sage Publications.

Phillips, A. (2003). When culture means gender: Issues of cultural defence in the English courts. Modern Law Review, 66(4), $510-531$.

Pounder, J. S., \& Coleman, M. (2002). Women-better leaders than men? In general and Educational Management it still all depends. Leadership \& Organization Development Journal, 23(3), 122-133.

Roomi, M. A., \& Parrott, G. (2008). Barriers to development and progression of women entrepreneurs in Pakistan. Journal of Entrepreneurship, 17(1), 59-72.

Rosaldo, M. Z. (1974). Woman, culture, and society: A theoretical overview. In M. Z. Rosaldo \& L. Lamphere (Eds.), Woman, culture and society (pp. 17-42). Stanford, CA: Stanford University Press.

Rubin, H., \& Rubin, I. (2005). Qualitative interviewing: The art of hearing data ( ${ }^{\text {nd }}$ ed.). Thousand Oaks, CA: Sage Publications.

Shakeshaft, C. (1987). Women in educational administration. Newbury Park, CA: Sage Publications.

Sperandio, J., \& Kagoda, A. (2008). Advancing women into educational leadership in developing countries: The case of Uganda. Advancing Women in Leadership, 24, 1-14.

Strauss, A., \& Corbin, J. (1990). Basics of qualitative research: Grounded theory procedures and techniques. Newbury Park, CA: Sage Publications.

Strauss, A., \& Corbin, J. (1997). Grounded theory in practice. Newbury Park: Sage Publications.

Tran, H., White, C. M., Chow, M. S., \& Kluger, J. (2001). An evaluation of the impact of gender and age on QT dispersion in healthy subjects. Annals of Noninvasive Electro-cardiology, 6(2), 129-133.

Walford, G. (2001). Doing qualitative educational research: A personal guide to the research process. London: Continuum.

Weyer, B. (2007). Twenty years later: Explaining the persistence of the glass ceiling for women leaders. Women in Management Review, 22(6), 482-496.

Williams, E., \& Morrow, S. (2009). Achieving trustworthiness in qualitative research: A pan-paradigmatic perspective. Psychotherapy Research, 19(4), 576-582.

Wirth, L. (2001). Women in management: Closer to breaking through the glass ceiling. In M. F. Loutfi (Ed.), Women, gender, and work: What is equality and how do we get there (pp. 239-249). Geneva: International Labour Office. 